\title{
Contextual Effect of School on Nutrition Intake to Prevent Anemia Among Female Adolescents in Yogyakarta
}

\author{
Ailsa Clarissa Cynara ${ }^{1)}$, Eti Poncorini Pamungkasari²), Bhisma Murti' ${ }^{1)}$ \\ ${ }^{1)}$ Masters Program in Public Health, Universitas Sebelas Maret \\ ${ }^{2)}$ Faculty of Medicine, Universitas Sebelas Maret
}

Background: Inadequate nutritional intake can affect the body condition of young women, one of effects is increasing the incidence of anemia. The Health Belief Model theory can determine how a person will behave in determining the nutritional intake consumed every day, especially foods that can prevent anemia. This study aimed to determine the effect of the iron-supplemented program, intrapersonal and social factors on nutritional intake for anemia prevention among female adolescents in high school in Yogyakarta.

Subjects and Method: This study was an observational analytic study with a cohort retrospective approach. The sample was selected by purposive sampling with a sample size of 120 study subjects. Data were analyzed using multilevel linear regression analysis with the Stata 16 program.

Results: Nutritional intake for anemia prevention in female adolescents has increased with the iron supplement program $(b=0.24$; $95 \% \mathrm{CI}=0.15$ to $0.32 ; \mathrm{p}<0.001$ ), high family income $(b=0.16 ; 95 \% \mathrm{CI}=0.07$ to $0.24 ; \mathrm{p}=$ $0.001)$, high perceived susceptibility $(b=0.11$; 95\% $\mathrm{CI}=0.02$ to $0.20 ; \mathrm{p}=0.012)$, high perceived seriousness $(b=0.66 ; 95 \% \mathrm{CI}=0.56$ to
$0.76 ; \mathrm{p}<0.001)$, and high perceived benefit $(\mathrm{b}=$ $0.23 ; 95 \% \mathrm{CI}=0.13$ to $0.33 ; \mathrm{p}<0.001)$. Nutritional intake for the prevention of anemia among adolescent decreased with high perceived barrier $(b=-0.09 ; 95 \% \mathrm{CI}=-0.17$ to $-0.01 ; \mathrm{p}=$ 0.040). There was no contextual effect of school on nutritional intake for anemia prevention among female adolescent (ICC $=4.57 \%$ ).

Conclusion: There was an effect of the bloodsupplemented program, family income, and the Health Belief Model construct (perceived susceptibility, perceived seriousness, perceived benefits and perceived barriers) on nutritional intake for anemia prevention among female adolescent. There was no contextual effect of school on nutritional intake for anemia prevention among female adolescent.

Keywords: iron supplements, anemia, Health Belief Model

\section{Correspondence:}

Ailsa Clarissa Cynara. Masters Program in Public Health, Universitas Sebelas Maret. Jl. Ir. Sutami 36A, Surakarta 57126, Central Java. Email: ailsaclarissacynara@student.uns.ac.id. o82230233293.

Cite this as:

Cynara AC, Pamungkasari EP, Murti B (Year). Contextual Effect of School on Nutrition Intake to Prevent Anemia Among Female Adolescents in Yogyakarta. J Matern Child Health. 05(05): 490-499. https://doi.org/10.26911/thejmch.2020.05.05.04.

cc) (†) Journal of Maternal and Child Health is licensed under a Creative Commons Attribution-NonCommercial-ShareAlike 4.0 International License.

\section{BACKGROUND}

Anemia is a condition characterized by a reduced number of red blood cells or hemoglobin $(\mathrm{Hb})$ concentration. The prevalence of anemia in adolescents is $6 \%$ in developed countries and $27 \%$ in developing countries. In 2011, 29\% (496 million) of non-pregnant women and 38\% (32.4 million) pregnant women of aged 15-49 years old had anemia (WHO, 2014).

Based on data from the Indonesian Health Profile in 2018, in Yogyakarta, there were $54.60 \%$ of female adolescents who have received iron supplements. With this 
number subject, it was found that the prevalence of anemia in female adolescents aged 12-19 years old was 48.09\% (Basic Health Research, 2018).

One of the government programs, which is the distribution of iron supplements to female adolescents is listed in the 2016 Ministry of Health circular letter Number HK.03.03/V/0595/2016 concerning The Distribution of Iron Supplements to Female Adolescents and Women in Reproductive Age. Based on the results of Basic Health Research in 2018, female adolescents who received iron tablet supplements were $76.2 \%$ consisting of $80.9 \%$ who got IS at school and $19.1 \%$ said that they did not get it from school. Meanwhile, those who did not get IT at all were $23.8 \%$. The level of consumption of iron supplements per year which is $<52$ items is $98.6 \%$ and those who consume $\geq 52$ items are $1.4 \%$.

According to Basic Health Research in 2018, the prevalence of chronic energy deficiency (CED) in female adolescent was $36.3 \%$. Inadequate nutritional intake can affect the body condition of young women, one of the effects is increasing the incidence of anemia among female adolescents.

Health Belief Model (HBM) explain and predict health behavior by focusing on individual beliefs about health and health behavior (Murti, 2018). This shows that HBM may determine how a person will behave in determining the nutritional intake consumed every day, especially foods that can prevent anemia.

\section{SUBJECTS AND METHOD}

\section{Study Design}

This study was an observational analytic study with a cohort retrospective approach and a cross sectional study design.

\section{Population and Sample}

The population in this study were female adolescents in 10 High School in Yogya- karta. The sampling technique used in this study was purposive sampling.

The sample in this study were 120 adolescents in 10 High School in Yogyakarta who fulfilled the eligibility criteria for the sample. The type of data used in this study was primary data.

\section{Study Variables}

The dependent variable was nutritional intake for the prevention of anemia in adolescent. Independent variables were the program of iron tablet distribution, intrapersonal and social factors, perceived susceptibility, perceived seriousness, perceived threat, perceived benefit, perceived barrier, cues to action, and self-efficacy.

\section{Operational Definition of Variable}

Parents' income is the income received by parents from work calculated on average per month with Rupiah nominal in order to fulfill the daily needs of life that affect children's nutritional intake. Income is measured through the Yogyakarta Regional Minimum Wage. Measuring tool using a questionnaire sheet, measurement scale of categorical data (o: Low Income $<\mathrm{Rp}$ 1,704,608 dan 1: High Income $\geq \mathrm{Rp}$ 1,704,608).

Parental education is the last formal level of education that parents have undergone which affects the family income and nutritional intake. The measuring instrument used a questionnaire sheet, the measurement scale was categorical data (o: if the mother's last education was basic education $<12$ years (elementary school, junior high school) and 1: if the mother's last education was further education $\geq 12$ years (senior high school, college).

The iron supplements distribution program is the supplementation of iron supplements at a dose of 1 tablet a week. The measuring instrument used a questionnaire sheet. The scale of measurement for categorical data (o: low, if they do not 
consume iron supplements once a week and 1: high, if they consume iron supplements once a week).

Nutritional intake for anemia prevention is food consumed by daily study subjects which is described through several items of questions about foods that can reduce the risk of anemia in detail in order to avoid inappropriate answers (bias). The measuring tool used a questionnaire sheet. Continuous data measurement scale at the time of data collection. For the purposes of data analysis, continuous data was converted into dichotomous data (o: low nutritional intake, if the nutritional adequacy rate is $<70 \%$ and 1 : high nutritional intake, if the nutritional adequacy rate is $\geq 70 \%$ ).

Perceived susceptibility is a person's belief about his or her risk of experiencing a disease or health problem. The measuring tool used a questionnaire sheet. Measurement scale: continuous data at the time of data collection. For the purposes of data analysis, continuous data was converted into dichotomous data (o: low, if the score is $<50 \%$ and 1 : high, if the score is $\geq 50 \%$ ).

Perceived seriousness is a person's thinking about the disease or health problem he or she is suffering from. The measuring tool used a questionnaire sheet. Measurement scale: continuous data at the time of data collection. For the purposes of data analysis, continuous data was converted into dichotomous data (o: low, if the score is $<50 \%$ and 1 : high, if the score is $\geq$ $50 \%)$.

Perceived benefit is someone who feels the benefits when paying for health facilities and services when compared to the risk of illness. The measuring tool used a questionnaire sheet. Measurement scale: continuous data at the time of data collection. For the purposes of data analysis, continous data was converted into dichoto- mous data (o: weak, if the score is $<50 \%$ and 1: strong, if the score is $\geq 50 \%$ ).

Perceived barrier is an individual's evaluation of barriers to adopt new behaviors. The measuring tool used a questionnaire sheet. Measurement scale: continuous data at the time of data collection. For the purposes of data analysis, continuous data was converted into dichotomous data (o: strong, if the score is $\geq 50 \%$ and 1 : weak, if the score is $<50 \%$ ).

Perceived threat is an individual's perception of the possibility of contracting a disease. This encourages individuals to take action to prevent or cure disease. The measuring tool used a questionnaire sheet. Measurement scale: continuous data at the time of data collection. For the purposes of data analysis, continuous data was converted into dichotomous data (o: high, if the score is $\geq 50 \%$ and 1 : low, if the score is $<50 \%$ )

Cues to Action are events, people, or things that move to change the behavior. The measuring tool used a questionnaire sheet. Measurement scale: continuous data at the time of data collection. For the purposes of data analysis, continuous data was converted into dichotomous data (o: no, if the score was $<50 \%$ and 1 : yes, if the score was $\geq 50 \%$ ).

Self-efficacy is belief in one's own ability to do something. The measuring tool used a questionnaire sheet. Measurement scale: continuous data at the time of data collection. For the purposes of data analysis, continuous data was converted into dichotomous data (o: weak, if the score is $<50 \%$ and 1 : strong, if the score is $\geq 50 \%$ ).

\section{Study Instrument}

The data were collected by using questionnaire.

\section{Data Analysis}

Univariate analysis (continuous scale variables were described in terms of $n$, 
mean, SD, minimum, and maximum, meanwhile, categorical scale variables were described in terms of $\mathrm{n}$ and percent). Bivariate analysis (the relationship between two variables with a categorical scale in other words the difference in the percentage between two or more groups, statistically tested by Chi Square. The size of the relationship using OR (Odds Ratio). Multivariate analysis used a multilevel analysis model, namely multilevel multiple linear regression analysis. Level 1 for individuals and level 2 for school level. There was a significant school contextual effect if the ICC was $\geq 8-10$.

Table 1. Univariate Analysis of Iron Supplements Distribution

\begin{tabular}{lcc}
\hline Iron Supplements Program & n & \% \\
\hline No & 29 & 24.1 \\
Yes & 91 & 75.9 \\
\hline
\end{tabular}

There was a positive effect of family income on nutritional intake to prevent anemia. Female adolescents with high family income were 22.00 times more likely to get nutritional intake to prevent anemia than those with low family income (OR= 22.00; 95\% $\mathrm{CI}=6.77$ to 71.47 ; $\mathrm{p}<0.001$ ).

There was a positive effect of father's education on nutritional intake to prevent anemia. Female adolescents with a high father's latest education were 37.83 times more likely to get a high nutritional intake for anemia prevention compared to those with low father's education $(\mathrm{OR}=37.83$; 95\% $\mathrm{CI}=10.62$ to $134.73 ; \mathrm{p}<0.001$ ).

There was a positive effect of maternal education on nutritional intake to prevent anemia. Female adolescents with a high maternal education were 8.67 times more likely to get a high nutritional intake for anemia prevention compared to those with lowmaternal education $(\mathrm{OR}=8.67$; 95\% $\mathrm{CI}=3.12$ to 24.06 ; $\mathrm{p}<0.001$ ).

There was a positive effect of iron supplements program on nutritional intake

\section{Study Ethic}

The ethics of this study consisted of respect for person, informed consent, and justice. This study has obtained approval from the study ethics commission, Faculty of Medicine, Universitas Sebelas Maret with Number EC: KE/FK/1087/EC/2018.

\section{RESULTS}

Based on table 1, it is known that most of the study subjects who were not there consumed iron supplements were 29 (24.1\%) subjects while those who consumed iron supplements were 91 (75.9\%) subjects. to prevent anemia. Female adolescents who get high iron supplement program were 8.95 times more likely to get high nutritional intake for anemia prevention compared to those who get low iron supplements program $(\mathrm{OR}=8.95 ; 95 \% \mathrm{CI}=3.41$ to 23.51; $\mathrm{p}<0.001)$.

There was a positive effect of perceived susceptibility on nutritional intake to prevent anemia. Female adolescents who have high perceived susceptibility were 5.71 times more likely to get a high nutritional intake for anemia prevention compared to those with low perceived susceptibility $(\mathrm{OR}=5.71 ; 95 \% \mathrm{CI}=2.20$ to $14.86 ; \mathrm{p}$ $<0.001)$.

There was a positive effect of perceived seriousness on nutritional intake to prevent anemia. Female adolescents who have high perceived seriousness were 218.50 times more likely to get a high nutritional intake for anemia prevention compared to those with low perceived seriousness $(\mathrm{OR}=218.50 ;$ CI $95 \%=25.79$ to 1851.05; $\mathrm{p}<0.001)$. 
There was a positive effect of perceived benefit on nutritional intake to prevent anemia. Female adolescents who have high perceived benefit were 15.62 times more likely to get a high nutritional intake for anemia prevention compared to those with low perceived benefit $(\mathrm{OR}=15.62 ; 95 \%$ $\mathrm{CI}=5.10$ to $47.86 ; \mathrm{p}<0.001)$.

Table 2. Bivariate analysis of the effect of the iron supplements distribution program, intrapersonal and social factors on nutritional intake for anemia prevention in high school adolescents in Yogyakarta

\begin{tabular}{|c|c|c|c|c|c|c|c|c|}
\hline \multirow{3}{*}{$\begin{array}{l}\text { Independent } \\
\text { Variables }\end{array}$} & \multicolumn{8}{|c|}{ Nutritional Intake for Anemia Prevention } \\
\hline & \multicolumn{2}{|c|}{ Low } & \multicolumn{2}{|c|}{ High } & \multirow[b]{2}{*}{$\mathbf{O R}$} & \multicolumn{2}{|c|}{$95 \% \mathrm{CI}$} & \multirow[b]{2}{*}{$\mathbf{p}$} \\
\hline & $\mathbf{n}$ & $\%$ & $\mathbf{n}$ & $\%$ & & $\begin{array}{c}\text { Lower } \\
\text { limit }\end{array}$ & $\begin{array}{c}\text { Upper } \\
\text { limit }\end{array}$ & \\
\hline \multicolumn{9}{|l|}{ Family Income } \\
\hline$<\operatorname{Rp} 1,704,608$ & 15 & 75.0 & 5 & 25.0 & 22.00 & 6.77 & 71.47 & $<0.001$ \\
\hline$\geq \operatorname{Rp} 1,704,608$ & 12 & 12.0 & 88 & 88.0 & & & & \\
\hline \multicolumn{9}{|c|}{ Father's Education } \\
\hline$<12$ Years & 17 & 81.0 & 4 & 19.0 & 37.83 & 10.62 & 134.73 & $<0.001$ \\
\hline$\geq 12$ Years & 10 & 10.1 & 89 & 89.9 & & & & \\
\hline \multicolumn{9}{|c|}{ Maternal Education } \\
\hline$<12$ Years & 13 & 59.1 & 9 & 40.9 & 8.67 & 3.12 & 24.06 & $<0.001$ \\
\hline$\geq 12$ Years & 14 & 14.3 & 84 & 85.7 & & & & \\
\hline \multicolumn{9}{|c|}{ Iron supplements program } \\
\hline No & 16 & 55.2 & 13 & 44.8 & 8.95 & 3.41 & 23.51 & $<0.001$ \\
\hline Yes & 11 & 12.1 & 80 & 87.9 & & & & \\
\hline \multicolumn{9}{|c|}{ Perceived susceptibility } \\
\hline Low & 13 & 50.0 & 13 & 50.0 & 5.71 & 2.20 & 14.86 & $<0.001$ \\
\hline High & 14 & 14.9 & 80 & 85.1 & & & & \\
\hline \multicolumn{9}{|c|}{ Perceived seriousness } \\
\hline Low & 19 & 95.0 & 1 & 5.0 & 218.50 & 25.79 & 1851.05 & $<0.001$ \\
\hline High & 8 & 8.0 & 92 & 92.0 & & & & \\
\hline \multicolumn{9}{|c|}{ Perceived benefit } \\
\hline Weak & 14 & 70.0 & 6 & 30.0 & 15.62 & 5.10 & 47.86 & $<0.001$ \\
\hline Strong & 13 & 13.0 & 87 & 87.0 & & & & \\
\hline \multicolumn{9}{|c|}{ Perceived barrier } \\
\hline Weak & 16 & 57.1 & 12 & 42.9 & 3.85 & 1.52 & 9.77 & 0.008 \\
\hline Strong & 77 & 83.8 & 15 & 16.3 & & & & \\
\hline \multicolumn{9}{|c|}{ Perceived threat } \\
\hline Low & 1 & 6.3 & 15 & 93.8 & 115.00 & 13.92 & 950.20 & $<0.001$ \\
\hline High & 92 & 88.5 & 12 & 11.5 & & & & \\
\hline \multicolumn{9}{|l|}{ Cues to Action } \\
\hline No & 13 & 65.0 & 7 & 35.0 & 11.41 & 3.88 & 33.55 & $<0.001$ \\
\hline Yes & 14 & 14.0 & 86 & 86.0 & & & & \\
\hline \multicolumn{9}{|l|}{ Self efficacy } \\
\hline Weak & 18 & 62.1 & 11 & 37.9 & 14.91 & $5 \cdot 39$ & 41.26 & $<0.001$ \\
\hline Strong & 9 & 9.9 & 82 & 90.1 & & & & \\
\hline
\end{tabular}

There was a positive effect of perceived threat on nutritional intake to pre-
There was a positive effect of perceived barrier on nutritional intake to prevent anemia. Female adolescents who have high perceived barrier were 3.85 times more likely to get a high nutritional intake for anemia prevention compared to those with low perceived barrier $(\mathrm{OR}=3.85 ; 95 \%$ $\mathrm{CI}=1.52$ to $9.77 ; \mathrm{p}=0.008$ ). 
more likely to get a high nutritional intake for anemia prevention compared to those with low perceived threat $(\mathrm{OR}=115.00$; 95\% $\mathrm{CI}=13.92$ to $950.20 ; \mathrm{p}<0.001$ ).

There was a positive effect of cues to action on nutritional intake to prevent anemia. Female adolescents who have high cues to action were $\mathbf{1 1 . 4 1}$ times more likely to get a high nutritional intake for anemia prevention compared to those with low cues to action $(\mathrm{OR}=11.41 ; 95 \% \mathrm{CI}=3.88$ to 33.55; $\mathrm{p}<0.001)$.

There was a positive effect of self efficacy on nutritional intake to prevent anemia. Female adolescents who have high self efficacy were 14.91 times more likely to get a high nutritional intake for anemia prevention compared to those with low self efficacy $(\mathrm{OR}=14.91 ; 95 \% \mathrm{CI}=5.39$ to 41.26 ; $\mathrm{p}<0.001)$.

Table 3. The results of multilevel multiple linear regression analysis of the effect of the iron supplements program, intrapersonal, and social factors on nutritional intake for anemia prevention among high school adolescents in Yogyakarta

\begin{tabular}{|c|c|c|c|c|}
\hline \multirow{2}{*}{ Independent Variable } & \multirow{2}{*}{$\begin{array}{c}\text { Regression } \\
\text { Coefficient (b) }\end{array}$} & \multicolumn{2}{|c|}{$95 \% \mathrm{CI}$} & \multirow{2}{*}{$\mathbf{p}$} \\
\hline & & Lower limit & Upper limit & \\
\hline \multicolumn{5}{|l|}{ Fixed effect } \\
\hline Family Income & 0.16 & 0.07 & 0.24 & 0.001 \\
\hline Iron Supplements Program & 0.24 & 0.15 & 0.32 & $<0.001$ \\
\hline Perceived Susceptibility & 0.11 & 0.02 & 0.20 & 0.012 \\
\hline Perceived Seriousness & 0.66 & 0.56 & 0.76 & $<0.001$ \\
\hline Perceived Benefit & 0.23 & 0.13 & 0.33 & $<0.001$ \\
\hline Perceived Barrier & -0.09 & -0.17 & -0.01 & 0.035 \\
\hline Constants & -0.33 & -0.46 & -0.20 & $<0.001$ \\
\hline \multicolumn{5}{|l|}{ Random effect } \\
\hline School Var (Constants) & & $<0.001$ & $<0.001$ & \\
\hline $\mathrm{N}$ observation $=120$ & & & & \\
\hline $\mathrm{N}$ group $=10$ & & & & \\
\hline Loglikelihood= 28.55 & & & & \\
\hline LR test vs regresi linear, & & & & \\
\hline $\mathrm{p}=7.8 \mathrm{e}-14$ & & & & \\
\hline $\mathrm{ICC}=<1 \%$ & & & & \\
\hline
\end{tabular}

There was an effect of family income on nutritional intake to prevent anemia. Female adolescents with high family income were 0.16 times more likely to get a high nutritional intake of anemia prevention than those with low family income $(\mathrm{b}=$ $0.16 ; 95 \% \mathrm{CI}=0.07$ to $0.24 ; \mathrm{p}=0.001)$.

There was an effect of iron supplements program on nutritional intake to prevent anemia. Female adolescents with high of iron supplements program were 0.24 times more likely to get a high nutritional intake of anemia prevention than those with low iron supplements program (b=0.24; 95\% $\mathrm{CI}=0.15$ to $0.32 ; \mathrm{p}<0.001$ ).
There was an effect of perceived susceptibility on nutritional intake to prevent anemia. Female adolescents with high perceived susceptibilitywereo.11 times more likely to get a high nutritional intake of anemia prevention than those with lowperceived susceptibility $(b=0.11 ; 95 \%$ $\mathrm{CI}=0.02$ to $0.20 ; \mathrm{p}=0.012$ ).

There was an effect of perceived seriousness on nutritional intake to prevent anemia. Female adolescents with high perceived seriousness were 0.66 times more likely to get a high nutritional intake of anemia prevention than those with low perceived seriousness $(b=0.66 ; 95 \% \mathrm{CI}=$ 0.56 to $0.76 ; \mathrm{p}<0.001)$. 
There was an effect of perceived benefit on nutritional intake to prevent anemia. Female adolescents with high perceived benefit were 0.23 times more likely to get a high nutritional intake of anemia prevention than those with low perceived benefit ( $b=0.23 ; 95 \% \mathrm{CI}=0.13$ to $0.33 ; \mathrm{p}<0.001$ ).

There was an effect of perceived barrier on nutritional intake to prevent anemia. Female adolescents with high perceived barrier were 0.09 times more likely to get a high nutritional intake of anemia prevention than those with low perceived barrier $(b=-0.09 ; 95 \% \mathrm{CI}=-0.17$ to -0.01 ; $\mathrm{p}=$ 0.035).

There was no contextual effect of school on nutritional intake for anemia prevention $(\mathrm{SE}<0.01 ; 95 \% \quad \mathrm{CI}<0.01$ to $<0.01$; ICC $<1 \%)$.

\section{DISCUSSION}

The results of this study indicated that monthly family income has an effect on nutritional intake in preventing anemia. Female adolescents with high family income were 0.16 times more likely to get nutrition intake for anemia prevention than those with low family income $(b=0.16 ; 95 \%$ $\mathrm{CI}=0.07$ to $0.24 ; \mathrm{p}=0.001$ ). Family income is associated with jobs to fulfill nutritional needs (Akombi et al, 2017). Income is associated with purchasing power of food, the inability to buy diverse and nutritious foods by low-income families can lead to low nutritional intake among female adolescents (Kurniasari, 2017). Family income is related to the provision of family food, access to food in the family and adequate distribution of food within the family. Income affected the quality and quantity of nutritional intake for all family members (Elkholy et al, 2011).

The results of this study indicated that the program iron supplements program has an effect on nutritional intake to prevent anemia. Female adolescents with high iron supplements program were 0.24 times more likely to get high nutritional intake for anemia prevention compared to those with low iron supplements program $(b=0.24$; $95 \% \mathrm{CI}=0.15$ to $0.32 ; \mathrm{p}<0.001)$. Of the several causes of anemia, the main cause of nutritional anemia in female adolescent is a lack of dietary nutrient intake, while iron needs are relatively high for adolescents' daily needs and menstruation (Gupta, 2014). Female adolescents need to consume a variety of foods to fulfill their energy, protein and micronutrient (vitamins and minerals) needs because they are used for rapid growth, increased blood volume and increased hemoglobin. Important micronutrients needed for female adolescents are iron and folic acid (Balanced Nutrition Guidelines, 2014).

The results of this study indicated that there was an effect of perceived susceptibility on nutritional intake to prevents anemia. Female adolescents high perceived susceptibility were 0.11 units times more likely to get nutritional intake to prevent anemia than those with low perceived susceptibility $(\mathrm{b}=0.11 ; 95 \% \mathrm{CI}=0.02$ to 0.20 ; $\mathrm{p}=0.012$ ). According to research conducted by Onoruoiza in 2018, perceived susceptibility actually refers to a subjective assessment of risks to health problems. A person who admits that they have a low risk of disease is more likely to commit unhealthy behavior. Meanwhile, someone who views them as having a high risk of disease will be more likely to perform behaviors that reduce their risk of developing disease.

The results of this study indicated that there was an effect of perceived seriousness on nutritional intake to prevent anemia. Female adolescents with high perceived seriousness were o.66times more likely to get a high nutritional intake of anemia prevention than those with low perceived 
seriousness $(\mathrm{b}=0.66 ; 95 \% \mathrm{CI}=0.56$ to 0.76 ; $\mathrm{p}<0.001)$. The perceived seriousness of a disease will influence beliefs about the disease itself (Onoruoiza et al, 2015). Based on the results of Basic Health Research in 2018, the number of female adolescents with anemia aged 12-19 years old was $48.09 \%$. This shows the value of seriousness or severity that makes female adolescents willing to seek information and then apply nutritional intake to prevent anemia. This is because they do not want to get sick so they will make efforts to prevent the disease.

The results of this study indicated that there was an effect of perceived benefit on nutritional intake to prevent anemia. Female adolescents with high perceived benefit wereo.23times more likely to get a high nutritional intake of anemia prevention than those with low perceived benefit $(b=0.23 ; 95 \% \mathrm{CI}=0.13$ to $0.33 ; \mathrm{p}<0.001$ ). Perceived benefits as a condition that is believed to cause seriousness to encourage someone to behave that leads to change. The benefits that someone feels will affect preventive action (Murti, 2018). Perceived benefits affect a person's attitude change, a person will adopt healthy behavior when people feel the behavior is beneficial to improve their health (Alatawi, 2016).

The results of this study indicated that there was an effect of perceived barrier on nutritional intake to prevent anemia. Female adolescents with high perceived barrier were 0.09 times more likely to get a high nutritional intake of anemia prevention than those with low perceived barrier $(\mathrm{b}=-0.09 ; 95 \% \mathrm{CI}=-0.17$ to $-0.01 ; \mathrm{p}=$ 0.035). The results of the study were in accordance with the Health Belief Model (HBM) theory that in taking action to prevent the occurrence of a disease and seeking treatment, it is influenced by perceived barriers, which are obstacles that may be faced in taking an action. General obstacles experienced by a person in determining health measures or utilizing health services are dominated by personal constraints such as feeling lazy, unpleasant and so on (Rosenstock et al., 1988).

The results of this study indicated that there was no contextual effect of school on nutritional intake for anemia prevention. This was evidenced by the ICC score of $<1 \%$ (ICC <8-10\%). Besides questionnaire, the researcher also conducted observational data collection by directly observing the school canteen and UKS or PMR activities. Based on direct observation, the majority of the schools have similar canteens. The food sold was almost the same, for example meatballs, chicken noodles, rice and side dishes and other snacks. Furthermore, for UKS or PMR activities are routinely held once a week. This caused low percentage of ICC numbers which was $<1 \%$ (ICC $<8$ $10 \%)$.

The limitation of this study was that this study was a quantitative study so that the researcher was not able to dig up detailed information about daily dietary habits from the study subjects.

The conclusion of this study is that the program of iron supplements to female adolescent is effective in increasing nutritional intake for the prevention of anemia among female adolescent, family income affects nutritional intake for anemia prevention in female adolescent, the constructs (variables) of Health Belief Model (HBM) which are perceived susceptibility, perceived seriousness, perceived benefits and perceived barriers affect nutritional intake for anemia prevention in female adolescent and there is no contextual influence of school on nutrition intake for anemia prevention among female adolescents.

The theoretical implications of this study support the behavior change model of 
the Health Belief Model (HBM) theory. This theoretical model is a conceptual formulation to know individual perceptions whether they accept or not about their health. The variables assessed include the individual's desire to avoid pain, their belief that there is an effort to avoid the disease. The results of this study indicate that this theoretical model is relevant in assessing the effect of the iron supplements program, intrapersonal and social factors on nutritional intake for anemia prevention among female adolescent with the application of the Health Belief Model (HBM). This is explained from the influence of the iron supplements program, family income and the HBM construct on nutritional intake for anemia prevention among female adolescents.

The practical implications of this study explain that the factors that affect the nutritional intake of anemia prevention among female adolescent are the program of iron supplements, family income, the construct of the Health Belief Model (perceived susceptibility, perceived seriousness, perceived benefits and perceived barriers), However, the school contextual influence does not affect the nutritional intake of anemia prevention in female adolescent. The results found in this study can be taken into consideration by policy makers in the Yogyakarta City Government through the Health Office or the relevant Community Health Center (Puskesmas).

The implication of the methodology used in this study is an observational analytic study with a retrospective cohort approach. The design used was cross sectional. The sampling technique used purposive sampling to select female adolescents in 10 schools. The analysis used is multiple linear regression analysis with a multilevel approach, this analysis is appropriate because it can see the magnitude of the influence from the individual level and the contextual influence on nutritional intake for anemia prevention.

Suggestions for the health office are to disseminate information related to matters that affect the nutritional intake of anemia prevention in female adolescent evenly in every school in Yogyakarta City For schools to provide iron supplements regularly, UKS supervisor teachers actively schedule, assist and supervise the behavior of consuming iron supplements among female adolescents, conduct screening by applying the theory of the Health Belief Model (HBM) related to things that can increase nutritional intake to prevent anemia in female adolescent and collect data for those who have middle-to-low income economies so that they can be given assistance from the school or related official to be able to increase nutrition intake to prevent anemia. Suggestions for health institutions are to develop strategies in an effort to increase nutritional intake for anemia prevention in female adolescent and for further researchers, it is expected to study a wider area of research and develop deeper factors that affect the nutritional intake of anemia prevention among female adolescents.

\section{AUTHOR CONTRIBUTION}

All authors collect the data, did data analysis, and wrote the paper.

\section{CONFLICT OF INTEREST}

The study was conducted with no commercial or financial relationship which could be interpreted as a potential conflict of interest.

\section{FUNDING AND SPONSORSHIP}

None. 


\section{ACKNOWLEDGEMENT}

This study has been approved for its truth and authenticity based on novelty by the authors, supervisors and agencies in its implementation and preparation.

\section{REFERENCE}

Akombi (2017). Stunting, Wasting and Underweight in Sub-Saharan Africa: A Systematic Review. Int J Environ Res Public Health. 14 (8).

Alatawi YM, Kavookjian J, Ekong G, Alrayees MM. (2016). The association between health beliefs and medication adherence among patients with type 2 diabetes. Research in Social and Administrative Pharmacy. 1-12.

Elkholy TA, Naglaa, Hassanen HM, Rasha (2011). Demographic, sosio-economic factors and physical activity affecting the nutritional status of young children under five years. Journal of American Science. 7(10).

Ghupta A, Parashar A, Tahkur A, Sharma D, Bhardwai P, Jaswal S (2014). Combating iron deficiency anemia among school going adolescent girls in Hilly State of North India: effectiveness of intermittent versus daily administrations of iron acid tablets. Int J Prev Med. 5(11), 1475-9.

Kurniasari AD (2017). The relationship between education level, occupation and parental income with nutritional status of students at SD Hangtuah 6 Surabaya. Surabaya: Faculty of Sports Science, Universitas Negeri Surabaya.

Murti, B (2018). Health promotion and behavior theory. Karanganyar: Bintang Fajar Offset.

Onoruoiza SI, Musa, Umar BD, Kunle (2018). Iron deficiency among rural college girls: a result of poor nutrition and prolonged menstruation. Journal of Community Nutrition \& Health. 2(2).

Onoruoiza SI, Musa, Umar BD, Kunle (2015). Using health belief model as an intervention to non compliance wtih hypertension information among hypertensive patient. IOSR Journal of Humanities and Social Science (IOSR-JHSS). 20 (9).

Pedoman Gizi Seimbang (2014). Good nutrition, healthy nation. Jakarta: Kementrian Kesehatan

Riset Kesehatan Dasar (Riskesdas) (2018). Health research and development agency of the Ministry of the Republic of Indonesia in 2018. Jakarta: Departemen Kesehatan RI.

Rosenstock, I.M., Strecher, V.J. and Becker, M.H. (1988) Social learning theory and the health belief model. Health Education Quarterly. 15, 175-83

WHO (2014). Global nutrition targets 2025: anemia policy brief. Geneva: World Health Organization. 